
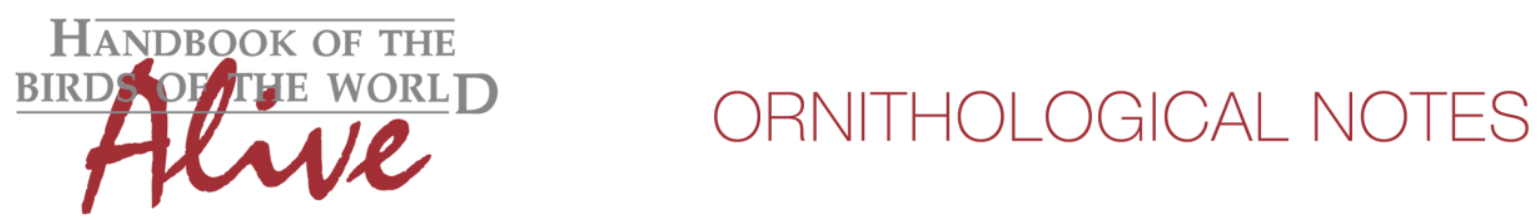

\title{
Notes on the vocalizations of Pine Grosbeak (Pinicola enucleator)
}

Peter Boesman

In the following we briefly analyze and compare voice of the different races of Pine Grosbeak (Pinicola enucleator). We also try to quantify the extent of any vocal differences using the criteria proposed by Tobias et al. (2010), as a support for taxonomic review. We have made use of sound recordings available on-line from Xeno Canto (XC).

Song is a variable strophe of clear melodious whistles at about the same pitch (strophe duration c 2-3s, most notes between 2 and $4 \mathrm{kHz}$ ). There are only few recordings available from the vast Asian range. A few examples:

Old World

Norway

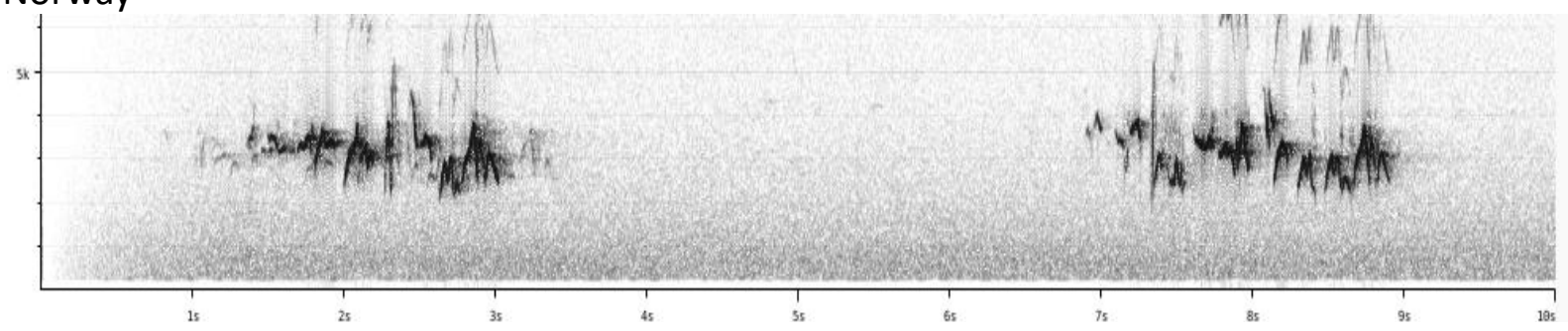

Kazachstan

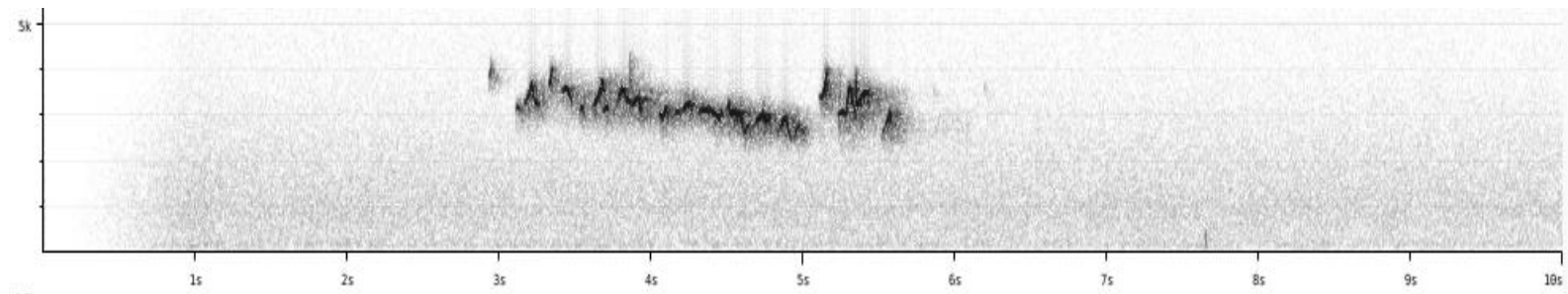

Japan

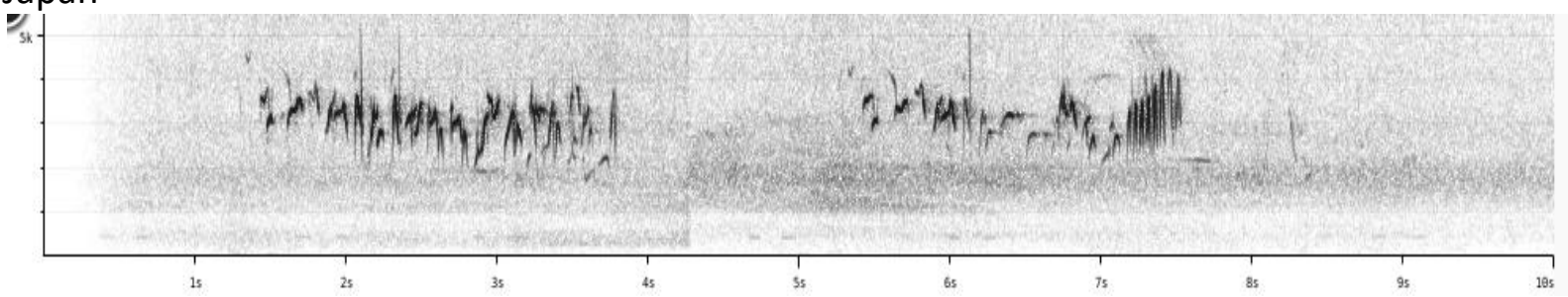



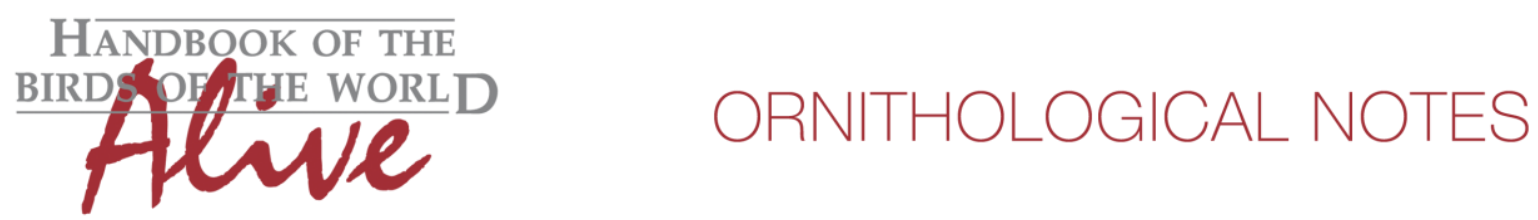

New World

Colorado

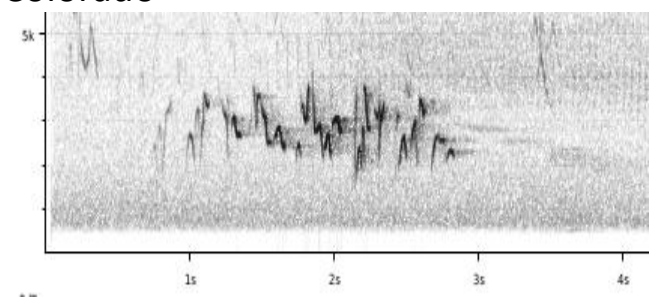

Canada

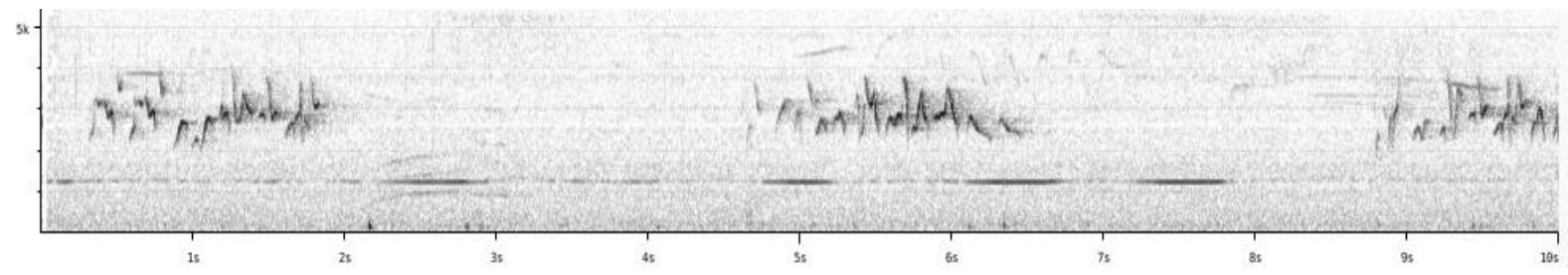

Alaska

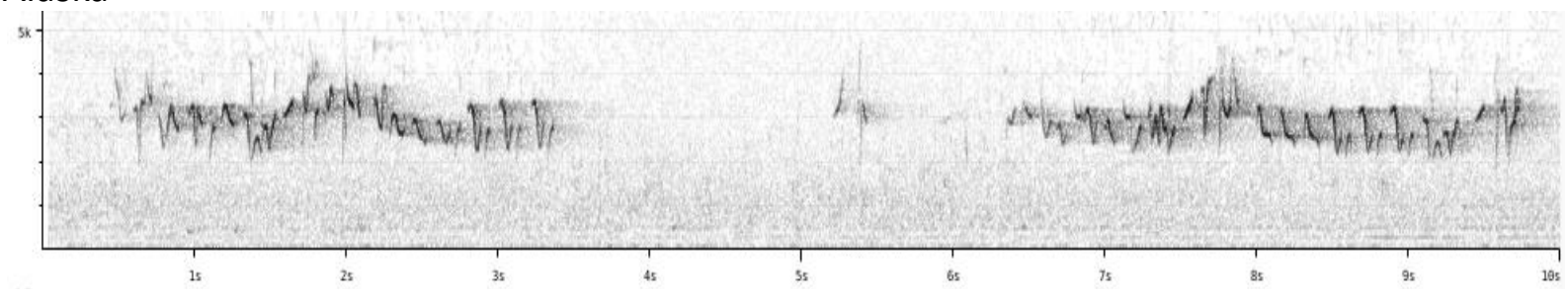

It would seem that song in Old and New World is quite similar. Basic sound parameters (phrase length, note length, pace, freq. range..) are all quite similar. Even many note shapes are similar.

The repertoire of call notes seems to be fairly extensive, and a much larger set of recordings would be needed to prove any consistent vocal difference between races.

Based on available recordings, we can only conclude that there are no obvious vocal differences.

This note was finalized on 20th May 2016, using sound recordings available on-line at that moment. We would like to thank in particular the many sound recordists who placed their recordings for this species on XC.

\section{References}

Tobias, J.A., Seddon, N., Spottiswoode, C.N., Pilgrim, J.D., Fishpool, L.D.C. \& Collar, N.J. (2010). Quantitative criteria for species delimitation. Ibis 152(4): 724-746. 


\section{Recommended citation}

Boesman, P. (2016). Notes on the vocalizations of Pine Grosbeak (Pinicola enucleator). HBW Alive Ornithological Note 353. In: Handbook of the Birds of the World Alive. Lynx Edicions, Barcelona. (retrieved from http://www.hbw.com/node/1252886 on 27 October 2016). 